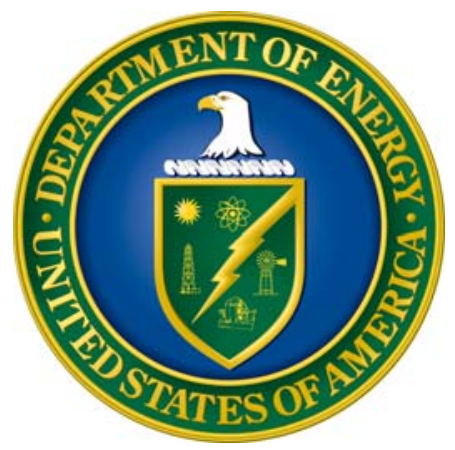

\title{
United States Department of Energy Office of Environmental Management Technology Development Report Fiscal Year 2010
}

October 2010 


\section{MESSAGE FROM THE DIRECTOR}

The mission of the Department of Energy's (DOE's) Office of Environmental Management (EM) is to clean up the environmental legacy of nuclear weapons research and production during the Cold War. That mission includes cleaning up nuclear waste, contaminated groundwater and soil, nuclear materials, and contaminated facilities covering two million acres of land in thirtyfive states. EM's principal program goals include timely completion of tank waste treatment facilities, reduction of the life-cycle costs and acceleration of the cleanup of the Cold War legacy, and reduction of the EM footprint.

The mission of the EM Technology Innovation and Development program is to transform science and innovation into practical solutions to achieve the EM mission. During fiscal year 2010 (October 2009September 2010), EM focused upon accelerating environmental cleanup by expeditiously filling identified gaps in available knowledge and technology in the EM program areas. This report describes some of the approaches and transformational technologies in tank waste processing, groundwater and soil remediation, nuclear materials disposition, and facility deactivation and decommissioning developed during fiscal year 2010 that will enable EM to meet its most pressing program goals.

\section{Yvette T. Collazo}

Office of Technology Innovation \&

Development

Office of Environmental Management

U.S. Department of Energy 


\section{TANK WASTE PROCESSING}

There are currently almost 90 million gallons of radioactive waste safely stored in 230 tanks at DOE's Hanford, Savannah River, and Idaho sites. The chemistry and forms of the wastes vary widely, as do the tanks containing them. Processing this radioactive tank waste has long been recognized as one of the most technologically complicated efforts in the Department. Retrieval, processing, and immobilization involve highly coordinated process steps that often require tailored solutions based on the specific wastes, tank conditions, and situations.

During fiscal year 2010, DOE EM took three major programmatic actions to expedite development of transformational technologies to optimize tank waste processing. The first was restructuring the Tank Waste Processing Program based on recommendations in the March 2009 Advice on the Department of Energy's Cleanup Technology Roadmap, Gaps and Bridge. In that report, the National Research Council of the National Academies identifies five technology gaps directly applicable to the tank waste program. The second was sponsoring the Tank Waste System Integrated Project Team (IPT) to perform a technical evaluation of potential strategies to significantly improve the tank waste system. The IPT's Technical Evaluation of Strategies for Transforming the Tank Waste System issued in January 2010 recommends transformational waste processing strategies that are feasible but require technology development to be successful. Those actions culminated in the June 2010 issuance of the EM Tank Waste Research and Development Plan, which describes major multi-year initiatives to develop transformational technologies supporting the general tank waste strategy to safely retrieve, stabilize, and dispose of radioactive tank waste and close the waste tanks.

Pursuit of transformational waste processing strategies during fiscal year 2010 has resulted in significant progress in the development of transformational waste processing technologies:

- Deploy at-tank processing to increase waste processing rates

o Small column ion exchange

o Rotary microfilter

- Increase waste loading to reduce high-level-waste canister production o Advanced silicate glasses

- Develop next-generation melters to improve waste processing

o International collaboration to develop Advanced Joule-Heated Ceramic and Cold Crucible Induction Melters

- Deploy alternative treatment processes to generate new waste forms and reduce the volume of waste

o Fluidized bed steam reforming

- Develop advanced separations processes to accelerate waste retrieval and minimize downstream high-level waste disposition

o Next-generation cesium solvent. 


\section{Small Column Ion Exchange}

Small column ion exchange (SCIX) is a sorbent column system to remove cesium, strontium, and select actinides from radioactive salt solutions in waste tanks. The low-activity treated salt waste will be sent to an on-site disposal facility. The cesium-, strontium-, and actinide-laden sorbent material and the high-level waste (HLW) sludge will be sent to the on-site vitrification facility to be immobilized in glass for interim storage and eventual permanent disposition. Ideally, the SCIX module will be deployed in-tank, using existing waste tanks for shielding. The Savannah River and Oak Ridge National Laboratories are maturing an elutable ion exchange resin, spherical resorcinol formaldehyde (sRF), for in-riser cesium decontamination with elution at the Savannah River and Hanford sites. In addition to completing radiation stability testing on sRF to confirm that it will accommodate high-dose feeds, a major undertaking

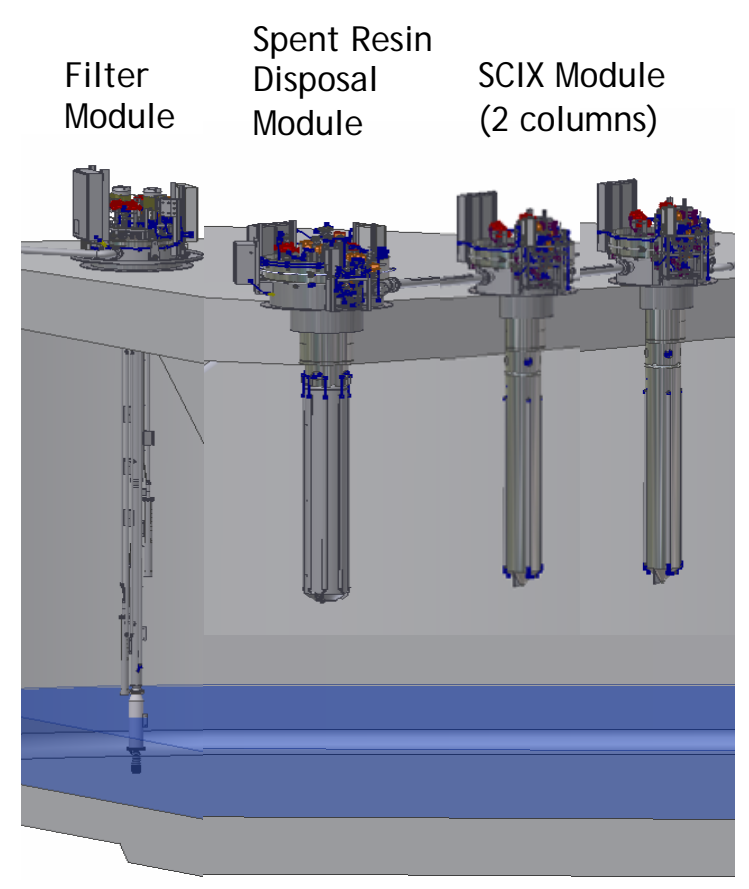
during fiscal year 2010 has been development of a non-acid eluant to mitigate tank corrosion during elution. Thirty-six potential non-acid eluant combinations were screened and five selected for additional testing, which will lead to selection of the most effective eluant. Deployment of SCIX at the Savannah River Site (SRS) will expedite salt waste processing in advance of start-up of the Salt Waste Processing Facility (SWPF) now under construction, reducing the current life-cycle by about six years and \$3.6 billion. Deployment of SCIX at Hanford could enable retrieval and treatment of salt waste from single-shell tanks nearly a decade ahead of the pretreatment capabilities of the Waste Treatment and Immobilization Plant (WTP) now under construction.

\section{SpinTek Rotary Microfilter}

The SpinTek ${ }^{\mathrm{TM}}$ rotary microfilter (RMF) is a compact filtration system that uses steel membrane filters mounted on rotating disks. The rotary action of the filter produces high shear at the membrane surface, reducing the fouling of the membrane, thus producing higher filtrate flow rates than the current technology of crossflow filtration. Increasing the solid-liquid separation rate increases the process throughput, reducing the time it takes to complete waste treatment. It also reduces the size and cost of the filtration equipment. The RMF is scheduled to be deployed in two applications at SRS. The first SRS application is clarification of the salt waste feed to the sorbent column to expedite SCIX. The second is continuous sludge washing to replace settle decantation to expedite preparation of HLW sludge batches for vitrification. The RMF also is proposed to process double-shell tank waste in conjunction with SCIX at Hanford. The Savannah

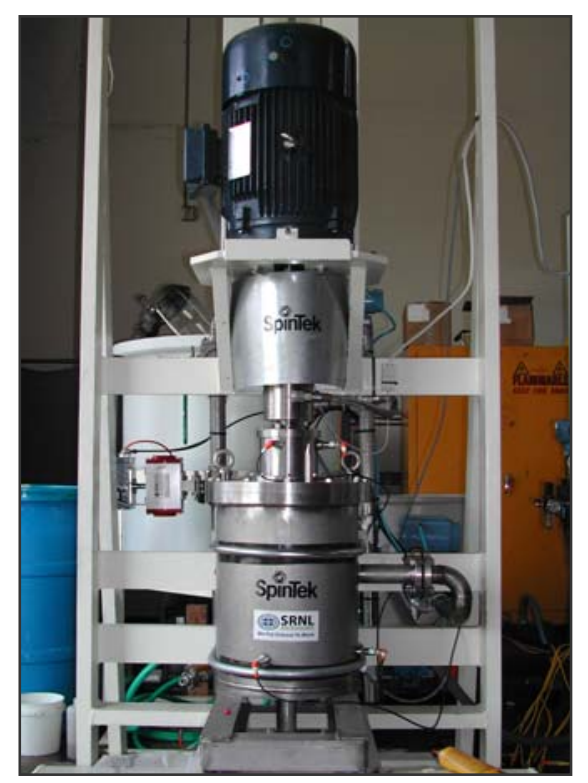

\section{G Environmental Management}


River and Oak Ridge National Laboratories in collaboration with SpinTek Systems are testing the second-generation full-scale rotary microfilter. In fiscal year 2010, a 1000-hour test at SpinTek using high-solids SRS simulated sludge feed to demonstrate the endurance of the newly designed RMF for sludge washing was completed, and development of a filter media with improved durability was begun. Development of the first of two Hanford radioactive waste surrogates for RMF testing was initiated.

\section{Advanced Silicate Glasses}

Increasing waste loading - increasing the amount of HLW incorporated into a glass waste form-has the potential to reduce the time and cost of waste processing exponentially. Various initiatives have previously achieved significant waste-loading improvements (e.g., increase from $28 \%$ to $38 \%$ ) in the Defense Waste Processing Facility (DWPF) at SRS. Pacific Northwest and Savannah River National Laboratories in collaboration with Catholic University of America are now developing advanced crystal-tolerant glasses and advanced glasses for difficult waste types, such as high alumina, high sulfur, and bismuth phosphate, along with the necessary predictive models to improve waste loading both in the DWPF and in the WTP under construction at Hanford. In fiscal year 2010, accomplishments include completion of the initial model for crystal-tolerant glass, development of crystal-tolerant glasses for high-iron wastes, extending high alumina glasses to cover the range of Hanford HLW compositions, and initiation of high-sulfate HLW glass development. In addition, results of a preliminary assessment of the effect on waste loading of reducing the liquidus temperature relative to the melter temperature suggest that constraints of the current vitrification process may be overcome through relatively low-risk changes. That preliminary assessment predicts that increasing the difference in temperature between the liquidus and the melter of one particular system (sludge batch 10 at SRS) may potentially achieve a waste loading of about 50\% compared to an upper waste loading limit of approximately $40 \%$ under current constraints.

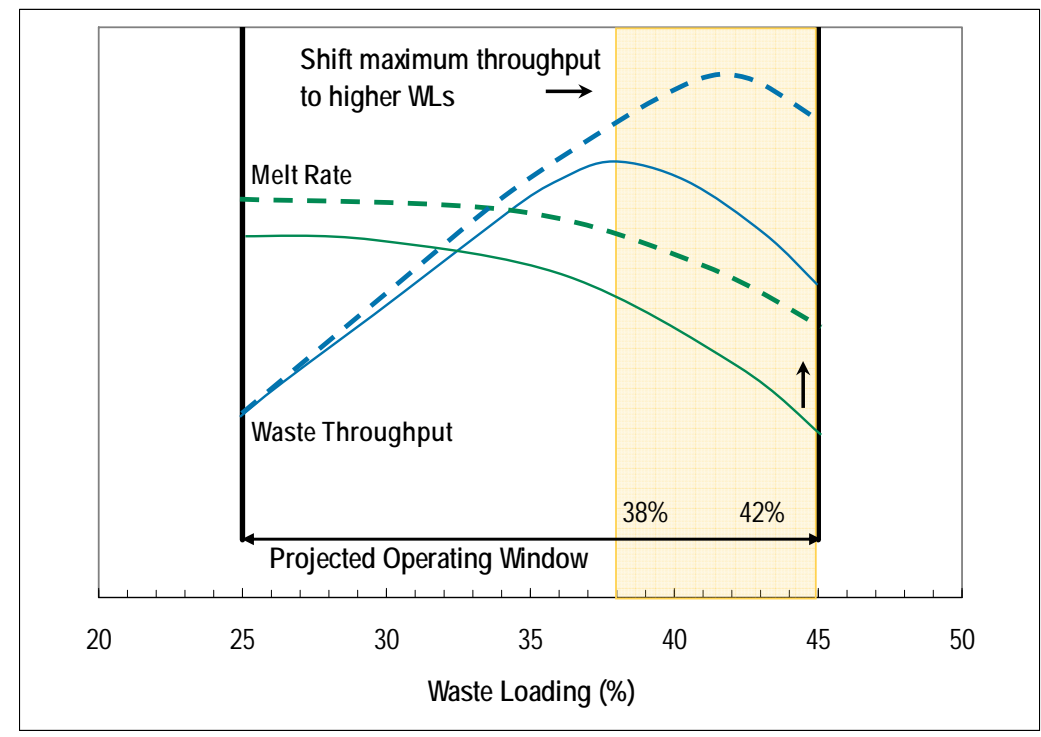

Waste Throughput Improvements from Strategic Glass

Formulation and Re-Evaluation of Process Control 


\section{Next-Generation Melters}

The Joule-heated ceramic melter (JHCM) technology in use in the DWPF at SRS has proven effective in vitrifying radioactive wastes. However, next-generation JHCMs and other advanced melter technologies (e.g., cold crucible induction melter, or CCIM) may be leveraged to dramatically reduce operational durations, potentially achieving life-cycle cost savings of billions of dollars. Active melt pool mixing using bubbler arrays provides drastic increases in melt rates for advanced JHCMs. Routine operation at melt temperatures significantly higher than the current JHCM can be maintained in the CCIM, significantly increasing processing rates and allowing for greater throughput and a smaller footprint. In March 2010, DOE EM sponsored the "Next-Generation Melter Technology” workshop. Experts from nine countries met in Washington, D.C., to discuss the current state of melter technologies, technology needs, and future direction. As a result, DOE EM has embarked on collaborative projects with partners world-wide to develop next-generation melters and associated systems for EM applications. In fiscal year 2010, progress included development of glass formulations to significantly increase waste loading, bench-scale testing of advanced melter technologies to demonstrate those improvements, and conceptual design of next-generation melter systems. Additionally, a next-generation melter innovation research call was planned to identify other transformational concepts to improve vitrification operations. Next-generation melter technologies are targeted for future deployment to treat HLW at the Hanford and Savannah River sites as well as low-activity waste (LAW) at Hanford and may be applied to other defense waste streams such as the sodium-bearing waste or calcine at Idaho.

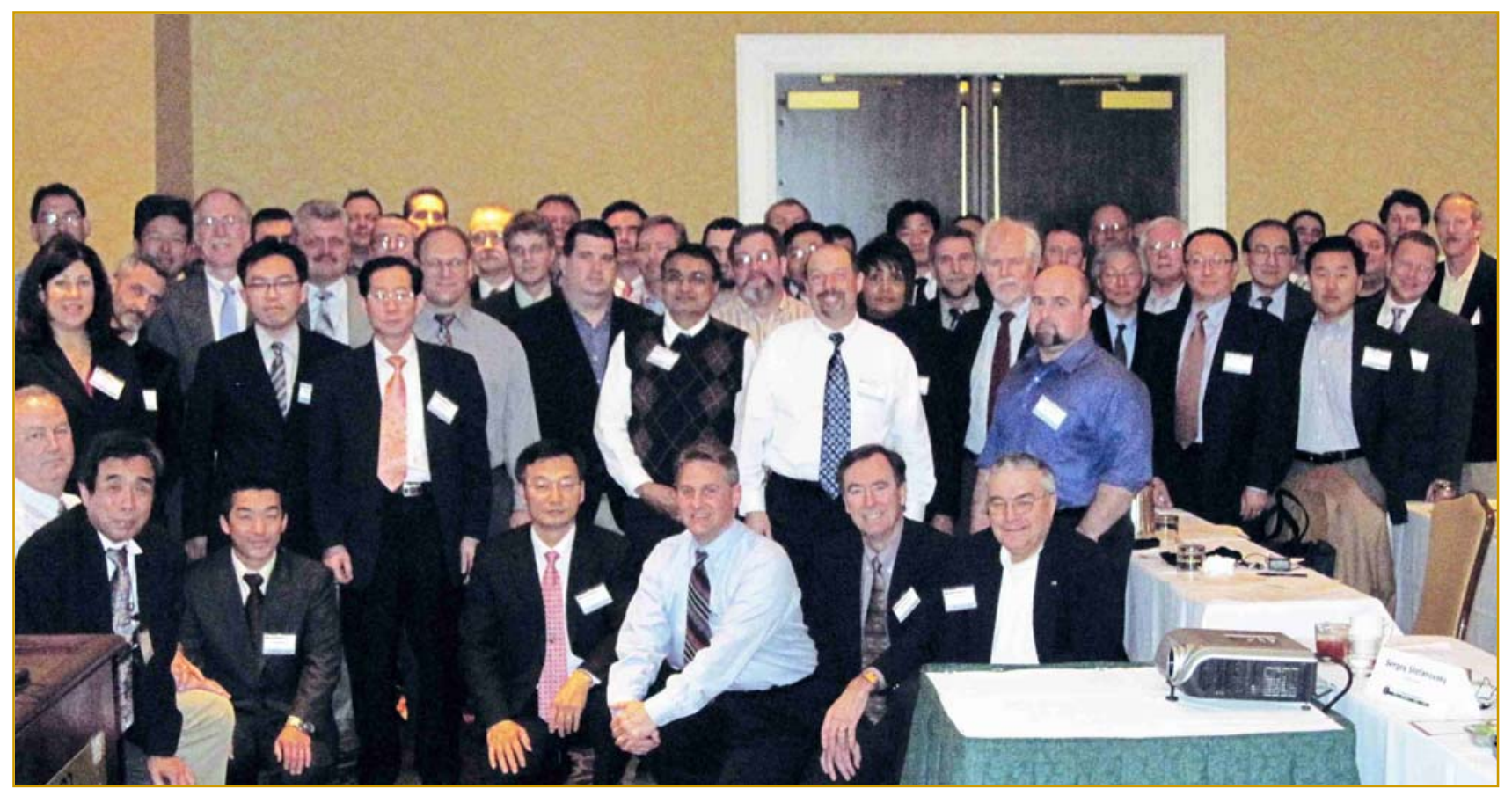

In March 2010, over 70 experts from 9 countries participated in the EM-sponsored Next Generation Melter Technology workshop in Washington, DC. 


\section{Fluidized Bed Steam Reforming}

The THermal Organic Reduction (THOR) Treatment Technologies (TTT) fluidized bed steam reforming (FBSR) technology converts radioactive liquid wastes to solid aluminosilicate or carbonate particles suitable for disposal or vitrification. A coordinated effort of Pacific Northwest National Laboratory, Savannah River National Laboratory (SRNL), Washington River Protection Solutions, and TTT is confirming the effectiveness of FBSR for treating multiple wastes as well as the environmental durability of the mineralized waste forms. Planned uses for FBSR include treatment of sodium-bearing waste at Idaho to produce a stable waste form suitable for disposal off site and treatment of Tank 48 waste containing organic cesium tetraphenyl borate at SRS to enable downstream processing and vitrification. FBSR to produce a sodium-alumino-silicate (NAS) waste form is a promising technology to supplement treatment of LAW to meet approved closure deadlines at Hanford. During fiscal year 2010, the challenge of demonstrating the capability of FBSR technology to process lower-activity waste into a final waste form suitable for disposal in the Hanford Integrated Disposal Facility (IDF) was tackled. Generation of the data and models for a technically defensible evaluation of the FBSR NAS monolithic waste form for Hanford LAW was begun to be followed by development of a complete waste form source term model required for IDF performance asessment. The first two actual Hanford waste samples were decontaminated of cesium at Hanford and shipped to SRNL for FBSR treatment and testing. In addition, SRNL tested an amended SRS DWPF radiological waste sample emulating future Hanford melter waste.

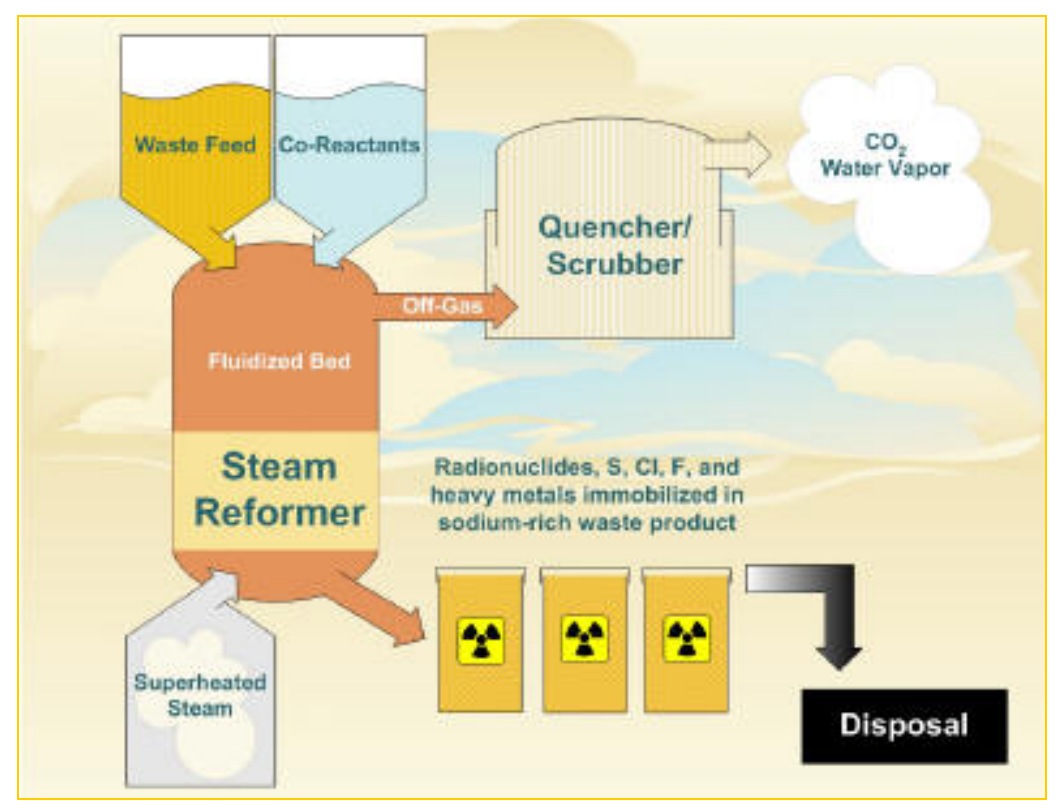




\section{Next-Generation Cesium Solvent}

The next-generation caustic-side solvent extraction (NG-CSSX) process provides a transformational tool for the removal of cesium from radioactive salt waste. It features dramatically enhanced ability to decontaminate the waste for on-site disposal and to concentrate the cesium for vitrification, with markedly increased throughput and

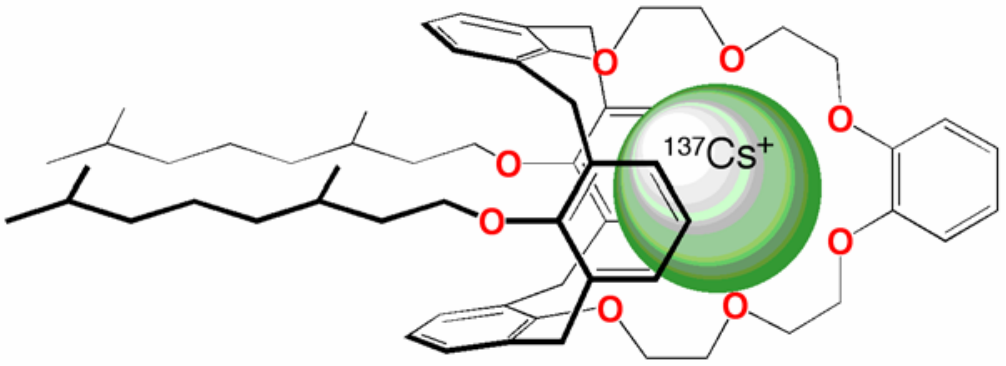

MaxCalix with captured cesium ion compacted footprint. The Modular CSSX Unit (MCU) at SRS is a pilot-scale facility designed to treat a small inventory of low-curie waste at limited throughput until the SWPF under construction at SRS comes on line. Designed for a modest decontamination factor (DF) of 12 for the interim treatment of a few million gallons of lowcurie feed, MCU has successfully operated since 2008 at 4-6 gpm, decontaminating nearly one million gallons of waste. However, about 34 million gallons of salt waste still to be processed remain in the tank farm inventory. In fiscal year 2010, research efforts by the Oak Ridge and Savannah River National Laboratories have delivered the solvent chemistry of the NG-CSSX process that will transform the performance of MCU so that it will deliver a DF of 40,000 and a concentration factor (CF) of 15 at waste throughputs as high as 12 gpm. The next-generation solvent system employs a new, more soluble calixarene extractant called MaxCalix, and the stripping is accomplished by a vitrification-friendly dilute boric acid solution. Implementation in MCU will enable the facility to process a full spectrum of salt wastes, boost throughput, and increase its operational flexibility. The SWPF is designed to use the same process as the MCU but on a much larger scale. The performance of SWPF also can be improved with an easy-to-implement adaptation of the next-generation solvent system. The next-generation solvent also may allow near-tank modular waste processing at Hanford. 


\section{GROUNDWATER AND SOIL REMEDIATION}

DOE is tasked with remediating some of the largest groundwater and soil contamination problems in the world, in terms of the volume of affected groundwater and soil, number of plumes, complexity of hydrogeologic settings, and diversity of contaminant types. DOE must remediate 1.8 billion cubic meters of soil, groundwater, and sediment in highly diverse environments that are contaminated with organics, metals, and radionuclides. Current groundwater and soil remediation (GW\&S) challenges that will continue to be addressed in the next decade include cost-effective characterization, remediation, and monitoring of contaminants in groundwater and the vadose zone, i.e., the waterunsaturated sediment below the soil and above the groundwater.

The complexity of the GW\&S effort requires a multi-faceted R\&D program, consisting of multiple initiatives and field sites for applied research. The focus areas interconnect with one another to enable development and implementation of holistic remedial strategies based on a scientific understanding of the subsurface environment.

The near-term focus and funding have primarily targeted remediation technology enhancements and development of a high-performance modeling and simulation tool. The Office of Groundwater and Soil areas of focus include:

- Attenuation-Based Remedies for Chlorinated Solvents in Groundwater and the Vadose Zone

- Attenuation-Based Remedies for Metals and Radionuclides in Groundwater

- Advanced Remediation Methods for Metals and Radionuclides in the Vadose Zone

- Mercury Characterization and Remediation

- Advanced Simulation Capability for Environmental Management

\section{Attenuation-Based Remedies for Chlorinated Solvents in Groundwater and the Vadose Zone}

Chlorinated solvents are the most common subsurface contaminants at DOE sites. There is currently no path to closure for sites with aerobic conditions that retard natural attenuation of chlorinated solvents or with geologic "tight zones" in which the contamination is trapped. Sites are faced with long-term and costly source treatments, such as pump and treat and soil vapor extraction (SVE). This focus area is providing the technical bases and technologies that will allow transition from active treatments to more passive approaches that consume less energy, require less intervention, and yield contaminant plume shrinkage and site closure in an acceptable time frame. Promising enhanced attenuation efforts include development of a vegetable oil to stimulate microbial communities for bioremediation at the interface between the groundwater and the vadose zone and mass flux-based approaches for remediation. Enhanced attenuation increases the capacity of a system to mitigate contamination through manipulation of hydrology or geochemistry without significantly altering the path of the natural geochemical evolution of the waste site. Demonstration of the use of edible oils in both the vadose zone and the groundwater at the T-Area of SRS began in fiscal year 2009 and will continue through fiscal year 2011; data have been sufficiently positive to result in the South Carolina Department of Health and Environmental Control granting permission for the dismantling of the pump-and-treat system that treated the groundwater at this waste unit. In 2010, a demonstration was initiated at the M-Area of SRS for an amendment, or additive, newly developed by SRNL to treat residual chlorinated solvents bound in low-permeability (clay) areas in the vadose zone. Monitoring will be ongoing for several years to assess the effectiveness and sustainability of this new

\section{GM Environmental Management}


amendment in treating the chlorinated solvents. Next steps include October 2010 field-testing of passive flux-control remedies to replace SVE at the Hanford Site 200-PW-1 operable unit and development of user guides for enhanced attenuation, monitored natural attenuation, and transition from active to passive attenuation methods.

\section{Attenuation-Based Remedies for Metals and Radionuclides in Groundwater}

\section{Savannah River Site F-Area Applied Field Research Site}

Metals and long-lived radionuclides in the subsurface pose a substantial risk to human health and the environment. Unlike organic contaminants, they cannot be destroyed and must be remediated in one of two ways: 1) removing them from the subsurface by excavation or pumping to the surface or 2) immobilizing or detoxifying them in place with attenuation-based remedies. Removal, transportation, and subsequent treatment are expensive, incur risk to workers, and often generate waste streams that must then be dispositioned. This focus area is developing technical guidance, tools, and new approaches for attenuation-based remedies at sites with metal or radionuclide contamination in groundwater. The key to success is stabilizing or detoxifying the contaminants during the intervening hundreds to thousands of years between removal of the source of contamination and evolution of the waste site to its natural condition. The Biogeochemical Processes for Applied Subsurface Research Program is based at SRS's F-Area Groundwater Operable Unit, an active waste unit undergoing remediation. Progress made in 2010 at this F-Area Applied Field Research Site included trial deployment in June of diffusion samplers, which represent one approach to determining sorption parameters in situ. Samples were collected in July, August, and September. The trial of a second approach, a push pull test, was deployed in August. Additionally, during the second half of the fiscal year, data on the groundwater/ sediment system was collected

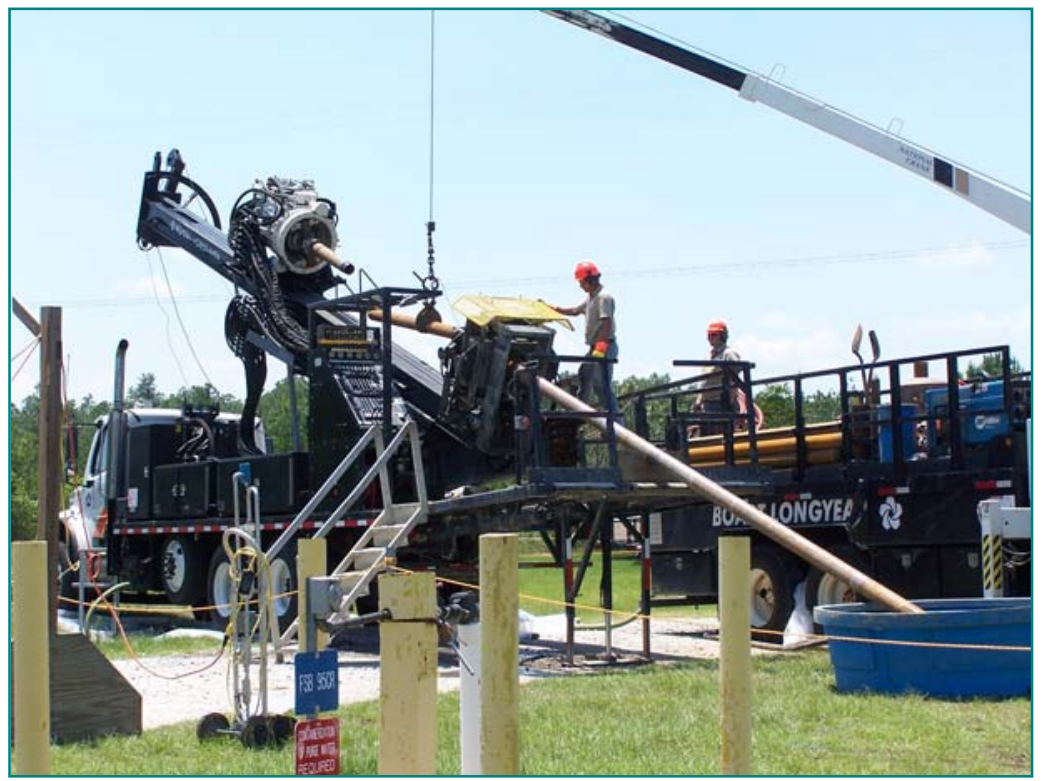

Diagonal drilling beneath F-Area seepage basin to support sampling preliminary to biogeochemical reaction path modeling. In August, a draft scenarios document was submitted for technical review to the core technical team leading this initiative and to the Interstate Technology Regulatory Council, a coalition of state environmental regulators, industry, and stakeholders working to streamline regulatory acceptance of innovative solutions to environmental challenges. Next steps in field work include shallow seismic tests, additional groundwater sampling, and a well survey using a gamma density tool. 


\section{Advanced Remediation Methods for Metals and Radionuclides in the Vadose Zone}

\section{Deep Vadose Zone Applied Field Research Center}

Remediation of heterogeneous vadose zone environments at DOE sites is uniquely challenging. Contaminating the subsurface are radionuclides, metals, organics, and complex mixtures originating from a number of sources, including intentional disposal in surface retention basins and unintended tank waste releases. In many cases, minimal historical information of the magnitude, timing, and content of contaminant releases exists, necessitating estimation of the source terms. Some of the released contaminants have limited mobility in the vadose zone and groundwater; others have migrated to regions deep within the vadose zone, reaching the groundwater in some locations and posing the threat of doing so in others. That diversity makes it difficult to design and deploy remedial approaches and to monitor the long-term sustainability of remedial actions. This project is developing an integrated set of advanced technologies and strategies for remediating vadose zone environments, including foam-based delivery technology for emplacement of remedial amendments, advanced geophysical monitoring capabilities with four-dimensional visualization, and long-term natural marker monitoring capabilities. The Deep Vadose Zone Applied Field Research Center based at the Hanford site leverages DOE investments in basic science, applied research, and site operation to provide sites with viable remedial alternatives to current approaches to persistent contaminants and deep vadose zone contamination. This collaborative effort facilitates advancement of the scientific foundation needed to make sound and defensible remedial decisions that will successfully meet the cleanup goals for one of EM's most intractable problems in a manner that is acceptable to regulators. Progress in fiscal year 2010 included bench-testing to determine the effects on microfoam quality and stability of foam generation methods, concentrations of anionic and nonionic surfactants and foam stabilizing agents, and remedial amendments for technetium and uranium stabilization. Evaluation of the use of passivated (i.e., rendered chemically non-reactive), zero-valent iron tracers for monitoring foam delivery technology in deep vadose zone environments also was completed. Future activities will focus on: foam delivery technology and transport and fate of technetium in unsaturated environments; geophysical monitoring and continued modeling; and natural microbial community monitoring of unsaturated environments.
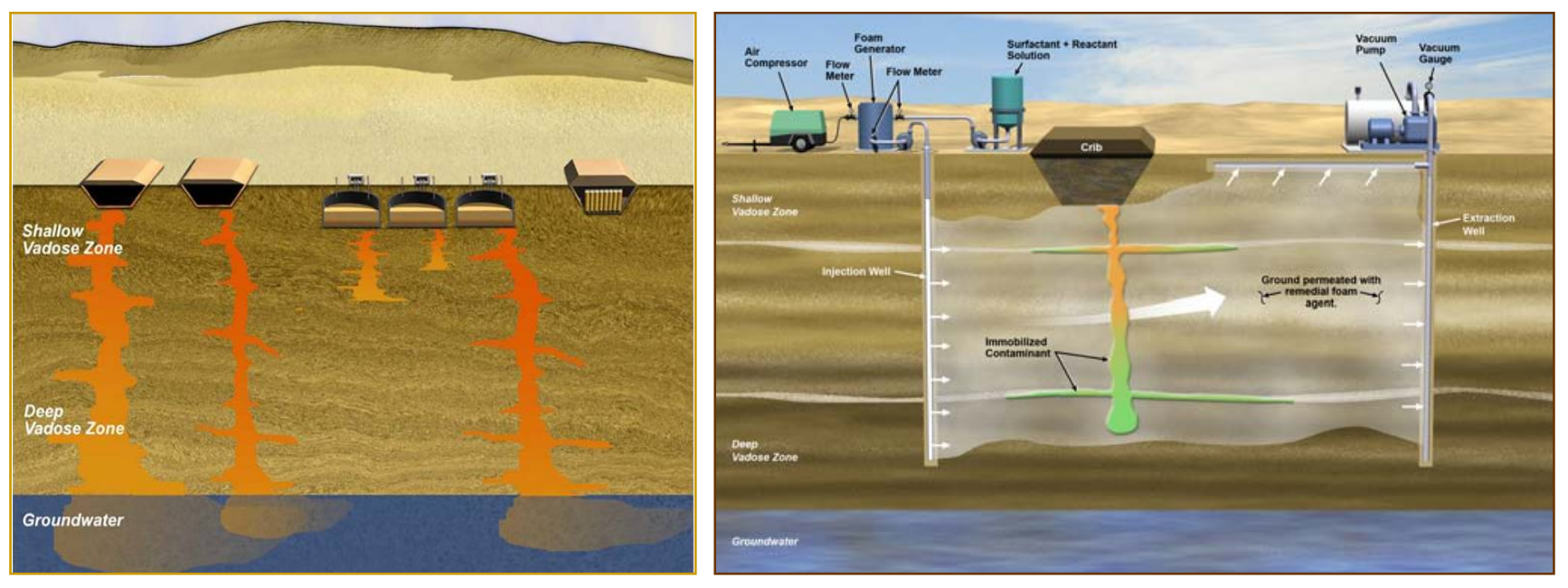


\section{Mercury Characterization and Remediation}

\section{Oak Ridge Mercury Field Remediation Center}

The Oak Ridge Integrated Facility Disposition Project (IFDP) involves demolishing and upgrading the infrastructure at the Y-12 National Security Complex (NSC) and the Oak Ridge National Laboratory (ORNL). IFDP requires simultaneous remediation of soils, groundwater, and surface water. The current estimated cost for mercury remediation at the Y-12 NSC alone is one billion dollars. The spatial distribution, speciation, and the extent of mercury contamination in the subsurface of the source zone remain poorly understood. Research efforts aim both to delineate mercury subsurface distribution and achieve mercury mass reduction in water. Remediation of water focuses primarily on point sources of mercury in dissolved

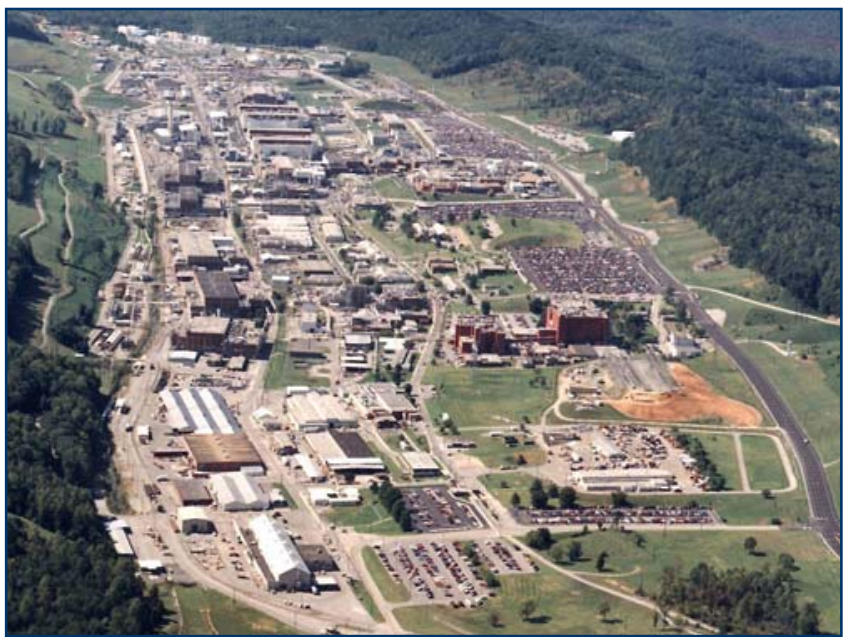

Y-12 National Security Complex oxidized form. Treatment technologies are being developed to reduce the flux of mercury from subsurface flow paths within the industrial complex to surface waters and prevent its conversion to methylmercury and subsequent bioaccumulation. This project is advancing along several avenues. During fiscal year 2010, EM has supported research at ORNL targeting removal of dissolved mercury at source zones where the mercury concentration is high and the volumetric flow is low. In addition, the ORNL team worked with SRNL to produce a conceptual model of waterborne mercury distribution and fluxes from known mercury use areas and existing outfalls at Y-12 NSC. ORNL researchers also developed and began to deploy a surface vapor detection method coupled with soil sampling to understand subsurface mercury speciation and distribution. A Mercury Field Remediation Center will be established in 2011 on the Oak Ridge Reservation, taking advantage of investments from basic science, applied research and site operation to promote integrated R\&D of

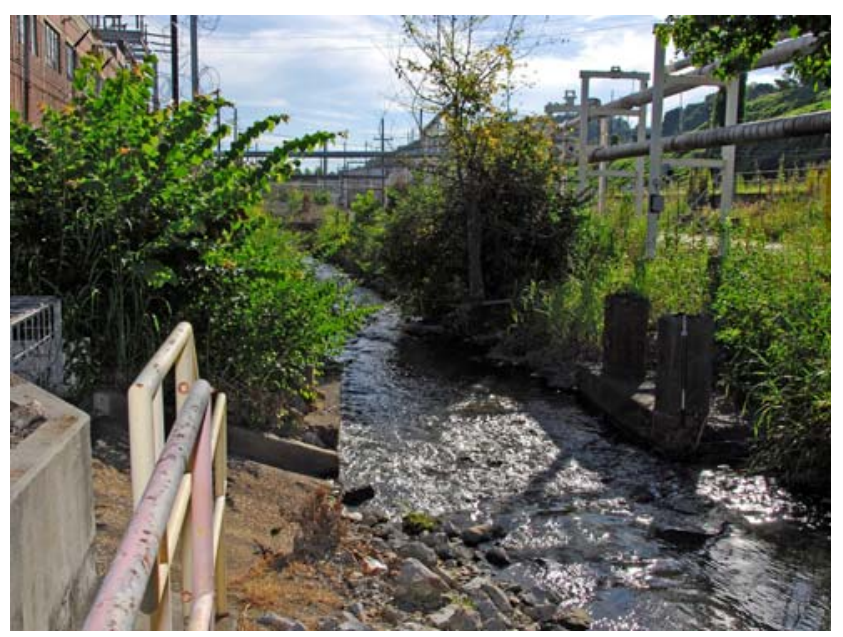

Outfall at Y-12 National Security Complex innovative technologies for mercury remediation across DOE sites. This collaborative effort facilitates development of the technological solutions that are acceptable to regulators and support remedial decisions to meet compliance goals. ORNL is leading the effort to set up the center and to provide its administrative and managerial infrastructure, including Management and Implementation Plans, a Research Safety Summary, and Health and Safety Plans. The center will facilitate user access and provide research materials, including mercurycontaminated soil, sediment, water, and groundwater samples for characterization and remediation $\mathrm{R} \& \mathrm{D}$ studies. 


\section{Advanced Simulation Capability for Environmental Management (ASCEM)}

EM started the Advanced Simulation Capability for Environmental Management (ASCEM) project in 2010 to develop a state-of-the-art scientific approach and high-performance computing tool to enhance understanding and characterization of contaminant movement in complex geologic environments. This allows more technically sound regulatory decisions regarding remediation to be made. The multi-laboratory ASCEM development team combines expertise in high performance computing (HPC) capabilities with expertise in environmental modeling, hydrology, geology, ecology, computational physics, chemistry, engineering and mathematics. The figure on the right shows results from a state-of-the-art calculation of flow and transport of a uranium plume at the Hanford site. ASCEM will build on advances in HPC, data management, uncertainty quantification, and visualization to integrate these functions on a single platform. The result will be an open-source, HPC modeling system for multiphase, multicomponent, multiscale subsurface flow and contaminant transport, and cementitious barrier and source-term degradation to aid in risk and performance assessments. In fiscal year 2010, the ASCEM program evaluated and documented existing EM site data, models and needs to develop the ASCEM requirements and design documents. The project recognized that solicitation of input from end-users was critical at the early stages of ASCEM

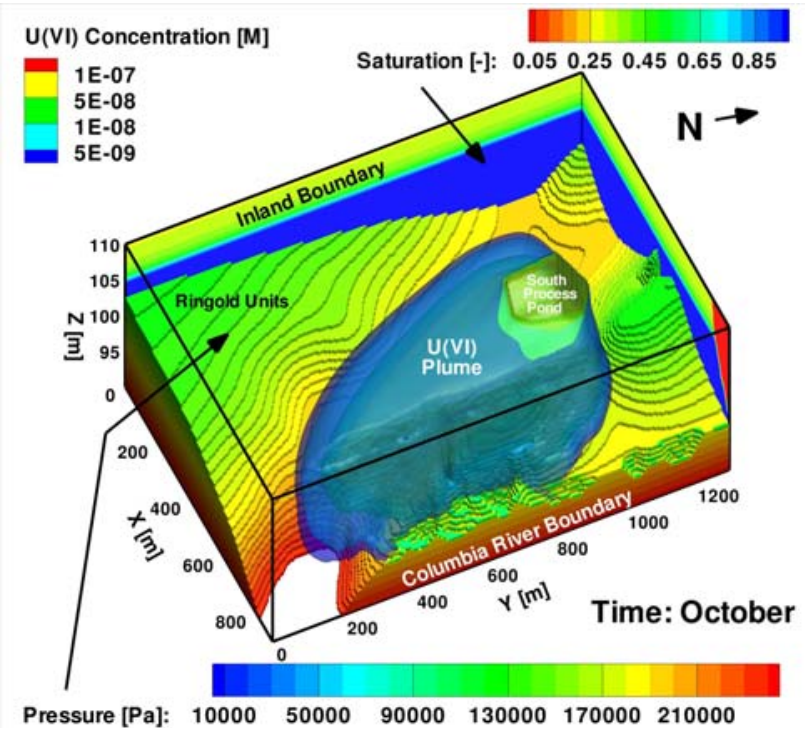

Simulation of uranium plume at the Hanford 300 area Lichtner, P.C. and G.E. Hammond, (2010) development to ensure that high priority user needs were incorporated into the framework. The ASCEM project completed, documented, and evaluated input from interviews with performance and risk assessment practitioners, decision makers, oversight personnel, and regulators involved in the EM cleanup mission as well as the Office of Science. That input has been incorporated into draft documents defining the ASCEM framework, including the requirements documents for High Performance Computing Process Models and Platform \& Integrated Toolsets. Next steps include defining collaborations with the DOE Offices of Fossil Energy and Nuclear Energy and successfully executing the ASCEM Phase 1 demonstration. The project will continue to engage end-users throughout the development of ASCEM to ensure that the framework is adopted across the DOE complex. 


\section{NUCLEAR MATERIALS DISPOSITION}

The EM Nuclear Materials Disposition (NM) Program is managing and defining disposition paths for spent nuclear fuel, challenging materials, and plutonium. In collaboration with other government organizations, the EM NM research and development (R\&D) program is ramping up to develop approaches and technologies to disposition those nuclear materials, including characterizing, treating/stabilizing, and packaging for disposal and risk-reduction during extended storage.

The NM R\&D program is divided into three areas:

- Spent Nuclear Fuel Management

- Challenging Materials Disposition

- Plutonium Materials Management and Disposition.

\section{Spent Nuclear Fuel Management}

DOE has over 2,400 metric tons of spent nuclear fuel (SNF) at mainly three sites: Hanford, Idaho, and Savannah River. Additional fuel is expected to be received into inventory over the next 25 years, primarily from domestic research reactors (DRRs) and foreign research reactors (FRRs).

The current inventory contains over 250 different fuel types that have different enrichment, fissile materials, cladding, and geometry. Included are spent fuel from DOE production reactors and R\&D reactors, the core debris from the Three-Mile Island reactor, and commercial power demonstration projects (e.g., Fort St.Vrain) as well as DRRs and FRRs. The physical condition of the fuels varies from intact assemblies to sectioned fuel pieces and failed cladding. The fuel is currently safely stored in varying configurations, including dry storage, wet storage, storage casks, and overpack containers.

All Hanford K-basin fuel has been placed in sealed dry storage in multi-canister overpacks ready for transportation and repository disposal. All EM-owned spent fuel at Idaho has been placed in various configurations of dry storage. All EM-owned spent fuel at Savannah River is in wet storage in L-basin.

DOE will continue to safely store and plan for future disposition of spent nuclear fuel, pending recommendations from the Blue Ribbon Commission on America’s Nuclear Future and subsequent DOE decisions.

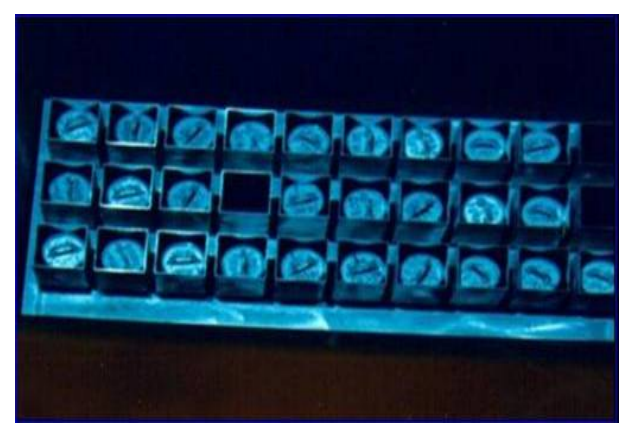

SNF in wet storage in L-basin at SRS

On September 15, 2010, the Nuclear Regulatory Commission issued a revised waste confidence rule that expresses confidence that used, or spent, nuclear fuel can be safely stored for at least 60 years beyond the licensed life of any reactor. To enable extended safe storage, the NM R\&D program will build upon current life management activities to develop an aging management program for SNF and storage facilities and demonstrate an adequate safety basis for long-term storage of SNF. Proposed activities to improve storage system integrity include developing remote inspection and characterization techniques for fuel storage canisters and contents, developing monitoring and inspection techniques to assess the condition of aging storage facilities and other safety-related 
components, and evaluating methodologies to extend the integrity of containment structures such as concrete.

Today's standard canisters provide a consistent, efficient means of storing a wide variety of types of SNF. However, the current shield plug design reduces the volume available for SNF within the canisters. Elimination of the shield plug requires that the final closure weld be performed in a high radiation field, potentially resulting in significant personnel exposure. A remotely operated system to perform closure welds, weld inspections, and any associated repairs will significantly reduce the number of canisters required for DOE SNFs and the associated costs while avoiding personnel exposure.

Designing a remote canister closure system that is compatible with an existing shielded cell will avoid much of the capital cost

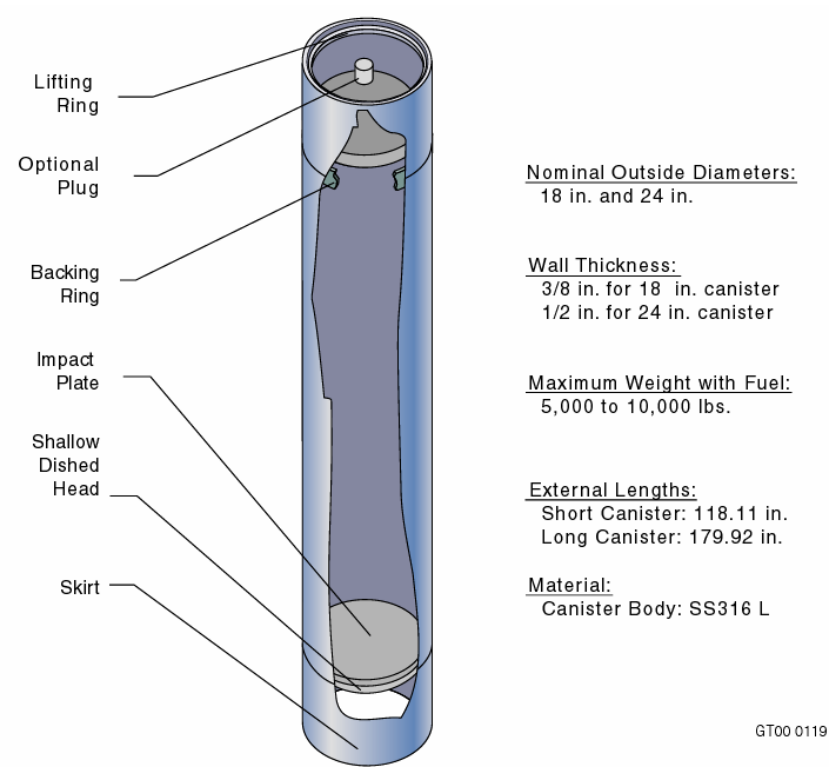

Typical DOE standard canister for SNF associated with packaging SNFs. Collaborative project interface between personnel developing and demonstrating a remote canister closure system at DOE’s National Spent Nuclear Fuel Program centered at Idaho National laboratory and site operations personnel will define interfaces and develop engineering documents to ensure compatibility and expedite deployment.

Also, a nickel-chromiummolybdenum alloy containing gadolinium is being developed to fabricate corrosion-resistant, longlasting internal baskets to facilitate canister loading of DOE SNF, provide structural support during operations, and provide a means to control criticality over geological timescales. Advanced neutron absorbing (ANA) materials reduce risks related to radiation criticality while enabling more waste to be packaged within the canister. They maintain geometry control during transportation and provide long-

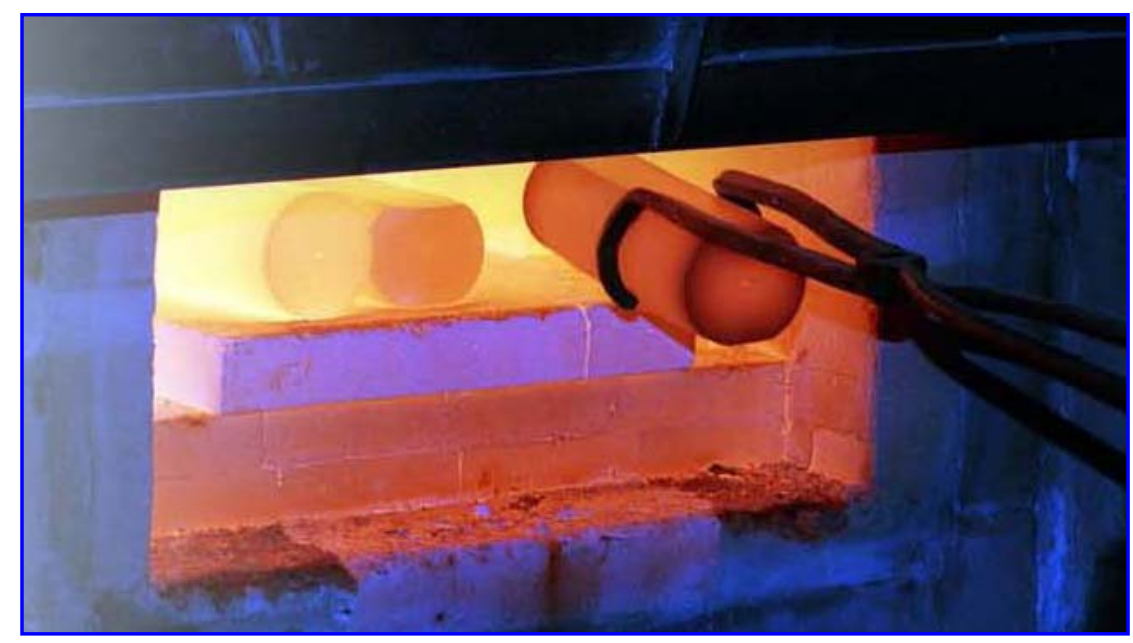

ANA material under development at INL term criticality controls. 
Investment in neutron absorbers ensures that DOE SNF is critically safe under fully flooded and degraded conditions. This investment decreases the number of SNF packages for long-term storage, reduces handling and materials costs, and avoids worker radiation exposure.

At the SRS L-Basin, aging-management activities have been applied to the fuel and basin structure. Activities include a surveillance program for chemistry monitoring of the fuel and storage rack materials to evaluate corrosion degradation and basin inspection and structural evaluation to assess the condition of the coating and concrete materials. The methodologies for aging management will continue to be advanced. For aluminum-clad SNF disposition, DOE is considering processing this fuel in H-Canyon at SRS for recovery of enriched uranium and down-blending to low enriched uranium for use in commercial nuclear fuel. Necessary for the efficient and effective use of such processing is the development of advanced technologies to minimize the high activity waste and to allow for maximum aluminum throughput. The technologies being considered include alternate reductant systems for solvent extraction and formic acid denitration. In addition, fundamental understanding of the flammable gas generated during the dissolution of high-aluminum content SNF is necessary to increase throughput. Both monitoring and modeling of gas generation are considered integral for success in this area.

\section{Challenging Materials Disposition}

Collectively referred to as "Challenging Materials” (CM), four primary types of materials that cannot be dispositioned "as is” have been identified throughout the DOE complex: Special Nuclear Material (SNM), Fission Products, Activated Metals, and Miscellaneous Materials. They include such diverse materials as mixed waste streams (i.e., those with both radioactive and hazardous constituents) that require remote/special handling, classified components, sealed sources, radioisotopic thermoelectric generators (RTGs), and other unique materials. The SNM category comprises primarily surplus plutonium inventories and is addressed separately because its management poses unique challenges.

In addition to EM, other DOE organizations, including the Offices of Science and Nuclear Energy and the National Nuclear Security Administration, hold CM inventories. Because many of the materials present similar stabilization, packaging, and disposition challenges, the EM NM Program is coordinating development of effective CM management and disposition strategies with those other organizations.

While none of the individual CM streams is large, taken together they represent a significant quantity of material requiring specialized action to enable disposition. A path forward has been established to address current impediments to disposition of the CM inventories and to lay the foundation for an integrated DOE CM R\&D plan.

First, a current and complete catalog of challenging materials in the DOE complex does not exist. The first initiative will establish a comprehensive database of information on DOE CM, including both materials and material storage systems.

Second, no common set of standards is in place for interim storage of CM. The second initiative will determine the intent of pertinent Code of Federal Regulation and DOE standards for nuclear

\section{EM Environmental Management}


materials management, evaluate present CM interim storage systems against those standards, and identify the best practices of preparation, packaging, and storage of each type of CM material.

Third, determinations of the ultimate disposition paths of CMs—storage in a particular form, disposal as a particular waste form, or recycling or reuse-have yet to be made. The third initiative will identify commonalities and differences in the disposition paths, published final disposal systems, and Waste Acceptance Criteria for the disposal systems among the DOE sites and will provide recommendations to improve/facilitate the sites' disposal paths for CM.

Accomplishment of those three initiatives will allow prioritization of needs for the CM Disposition Program and identification and development of handling, treatment, storage, and disposition strategies and technologies for high priority CM.

\section{Plutonium Materials Management and Disposition}

Up to 13 metric tons of surplus plutonium (Pu) are or will be safely stored at the K-Area Materials Storage facility at SRS using DOE Standard 3013 Stabilization, Packaging, and Storage of Plutonium-Bearing Materials, which provides direction for stabilizing and packaging surplus Pu-bearing metals and oxides that contain at least $30 \mathrm{wt} \%$ actinides and maintaining container integrity for at least 50 years. In addition to providing safe storage, EM has authorized the processing of some surplus $\mathrm{Pu}$ material in $\mathrm{H}$-Area at SRS.

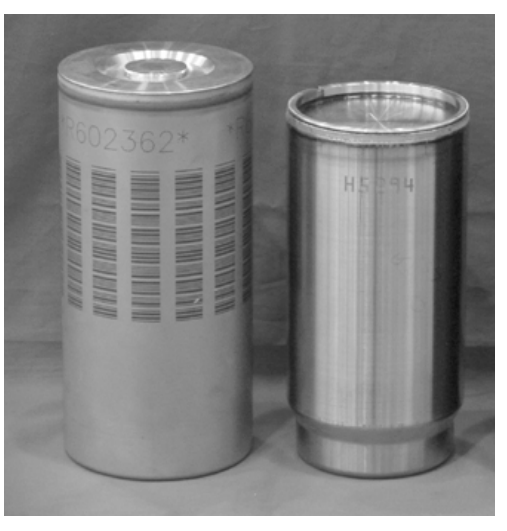

DOE 3013 Standard Containers

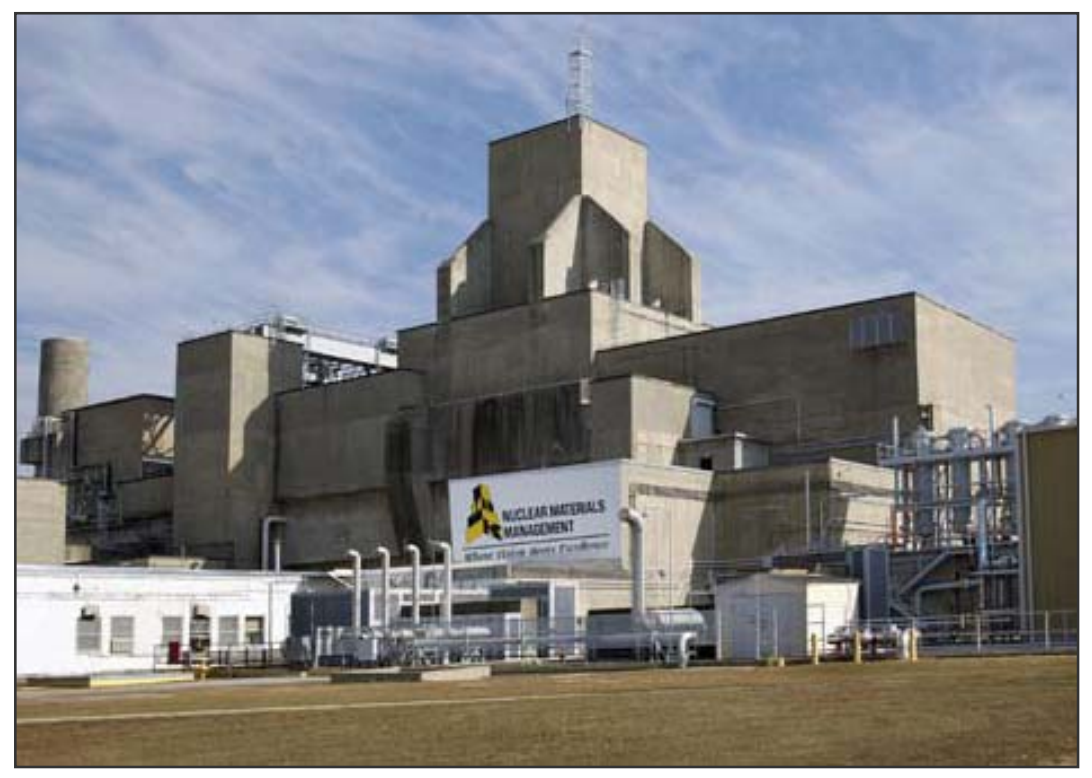

K-Area Materials Storage Facility at SRS

A key element of DOE S 3013 is surveillance to ensure continuing container integrity and to validate the technical basis for storage. EM's Pu container surveillance and associated R\&D activities have been focused on degradation mechanisms including pressurization and corrosion. Advanced nondestructive examination techniques including digital radiography have been used to characterize pressurization in the container. Destructive examination has been used to characterize potential corrosion and corrosion mechanisms in the container. Results of the surveillance and $\mathrm{R} \& \mathrm{D}$ activities will enable the validation of the storage basis and predict container integrity. 
SRNL and LANL developed an integrated corrosion program to improve the limited understanding of corrosive gas behavior within 3013 containers and the potential for stress corrosion cracking. Laboratory tests investigating the corrosivity of moist Pu oxide/ chloride salt mixtures, similar to those packaged within 3013 containers, on 304L and 316L stainless steel coupons showed that relative humidity affected the susceptibility of austenitic stainless steels to stress corrosion cracking.

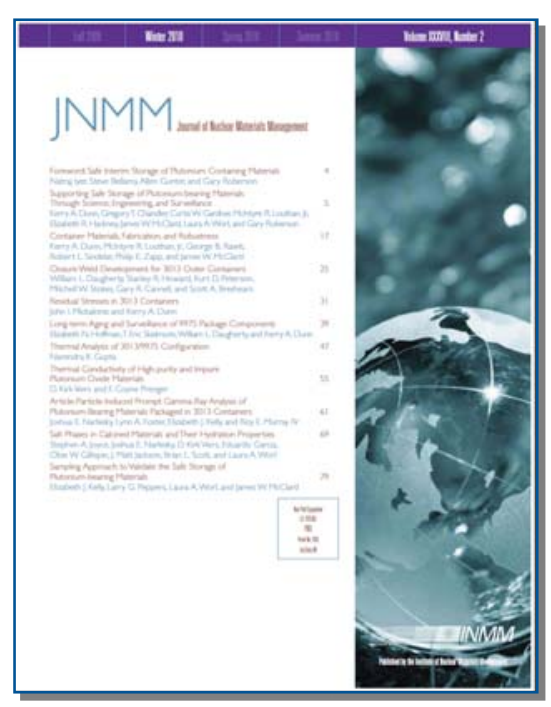

The results of the field surveillance and associated R\&D activities were disseminated through 21 peer-reviewed articles published in the Winter 2010 and Spring 2010 issues of the Journal of Nuclear Materials Management. Those articles provide the evidence for the safe storage of Pu within 3013 containers and outline the advancements in understanding of the performance of package materials.

In addition to providing safe storage for Pu materials, EM has authorized the processing of a limited amount (up to $600 \mathrm{kgs)} \mathrm{of}$ surplus $\mathrm{Pu}$ material in $\mathrm{H}$-Area at SRS. Metals will be processed in $\mathrm{H}$-Canyon and oxides in HB-Line. The Pu oxide processing in HBLine currently requires aggressive conditions due to the highly refractory nature of the Pu oxide materials. Furthermore, several of the Pu oxide materials have significant amounts of chloride, which pose a corrosion concern for the equipment in HB-Line.

For HB-Line to provide more effective processing, a transformational approach is needed. R\&D efforts have led to a shift in the operational strategy. Instead of brute force dissolution (strong acid, high temperatures, high fluoride) and exposing the HB-Line equipment to corrosive chlorides, pretreatment technologies are being explored that will eliminate the chloride corrosion concern and lead to milder dissolution conditions while at the same time improving the HB-Line throughput.

SRNL is developing two pretreatment technologies of Pu oxide materials that will be dissolved in HB-Line. Those two technologies are vacuum salt distillation and sodium peroxide fusion. Vacuum salt distillation removes sodium and potassium chloride salts from Pu materials, eliminating equipment corrosion concerns. Sodium peroxide fusion provides an effective treatment for dissolution of Pu-containing materials in a manner that also increases throughput. Both technologies have been successfully demonstrated on the laboratory scale.

Further R\&D is necessary for effective deployment of these technologies, especially if a broader scope of surplus Pu materials is identified for dissolution in H-Area. 


\section{DEACTIVATION AND DECOMMISSIONING}

EM's current Deactivation and Decommissioning (D\&D) life-cycle scope comprises over 3000 facilities, including over 1000 nuclear and radioactive buildings located across the DOE complex and accounting for close to 25 percent of the Department's total buildings and other structures, and nearly 47 percent of the Department's replacement plant value. The portfolio includes multiple nuclear production reactors, over 100 test and research reactors, multiple football-field-size gaseous diffusion plants, chemical processing plants, fuel and weapons component fabrication facilities, canyons and radionuclide separations facilities, laboratories, hundreds of miles of buried pipelines, and a myriad of other contaminated facilities. A large majority of the facilities to be decommissioned in the DOE complex are one-of-a-kind or unique to DOE with unprecedented scope and complexity. In many instances the needed technologies are yet to be developed or will require significant reengineering to be adapted to meet DOE needs. With the more complex D\&D projects scheduled into the out years, the opportunity exists to address needed technical improvements and advancements to achieve cost and schedule expectations.

The D\&D R\&D program supports the identification, development, and timely deployment of adaptive and transformational technologies that are needed for the safe closure of nuclear, radiological, and industrial facilities. Priority projects pursued in fiscal year 2010 that are expected to produce demonstrable D\&D benefits in the near future include:

Remote Radiological Characterization and Stabilization

- RadBall ${ }^{\mathrm{TM}}$

- Stack Characterization System

- Integrated Remote Fixative Spraying Platform

Decontamination

- DeconGel ${ }^{\mathrm{TM}}$

- Sodium Passivation

In situ Decommissioning

- Materials Behavior and Degradation

- Sensors and Monitoring

- Knowledge Management. 


\section{RadBall $^{\mathrm{TM}}$}

Many DOE facilities slated for D\&D pose hazards (radiological, chemical, and structural) that preclude safe use of traditional manual D\&D techniques. EM is developing remote technologies to characterize and stabilize conditions inside facilities prior to $D \& D$ to mitigate the risks to workers of potential radiological and chemical contamination and structural deterioration. One very promising technology to locate and quantify radiation hazards and sources is the RadBall $^{\text {TM }}$ invented by the National Nuclear Laboratory in the United Kingdom. The device consists of a colander-like outer shell that houses a radiation-sensitive polymer sphere. The outer shell works to collimate radiation sources, and those areas of the polymer sphere that are exposed react, becoming increasingly less transparent in proportion to the absorbed dose. The polymer sphere is imaged in an optical computerized

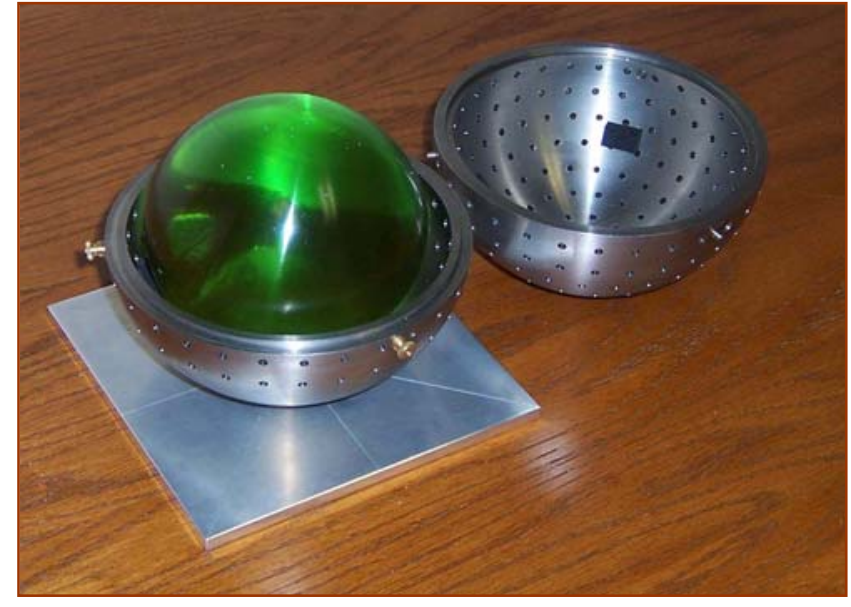

Two components of a RadBall ${ }^{\text {TM }}$ device: the outer collimation shell and the inner polymer core. axial tomography (CT) scanner developed at Duke University, which produces a high resolution 3dimensional map of optical attenuation coefficients that are proportional to absorbed dose. During fiscal year 2010, SRNL investigated the adaptation of RadBall ${ }^{\mathrm{TM}}$ technology to EM D\&D applications. After performing preliminary tests to identify the optimal dose and collimator thickness, SRNL then tested the ability of RadBall ${ }^{\mathrm{TM}}$ to characterize a hot cell with unknown radiation sources. Radiation tracks were visible in each trial. SRNL designed several RadBall ${ }^{\mathrm{TM}}$ accessories for future EM D\&D deployment. Since RadBall ${ }^{\mathrm{TM}}$ is a passive radiation detection device that contains no electronics and therefore cannot determine its location or orientation within a room, SRNL has developed a device (patent pending) called the Position and Orientation Determination System (PODS) to facilitate the spatial orientation of RadBall ${ }^{\mathrm{TM}}$. Other RadBall $^{T M}$ accessories invented by SRNL include a harness for RadBall ${ }^{\mathrm{TM}}$ deployment by crane or manipulator and a remotely controlled robot with video equipment for RadBall ${ }^{\mathrm{TM}}$ deployment in confined spaces and areas of low visibility. Next steps are to test deployment of all RadBall ${ }^{\mathrm{TM}}$ system components at a second national laboratory, Oak Ridge, identify any shortcomings, and modify the system accordingly.

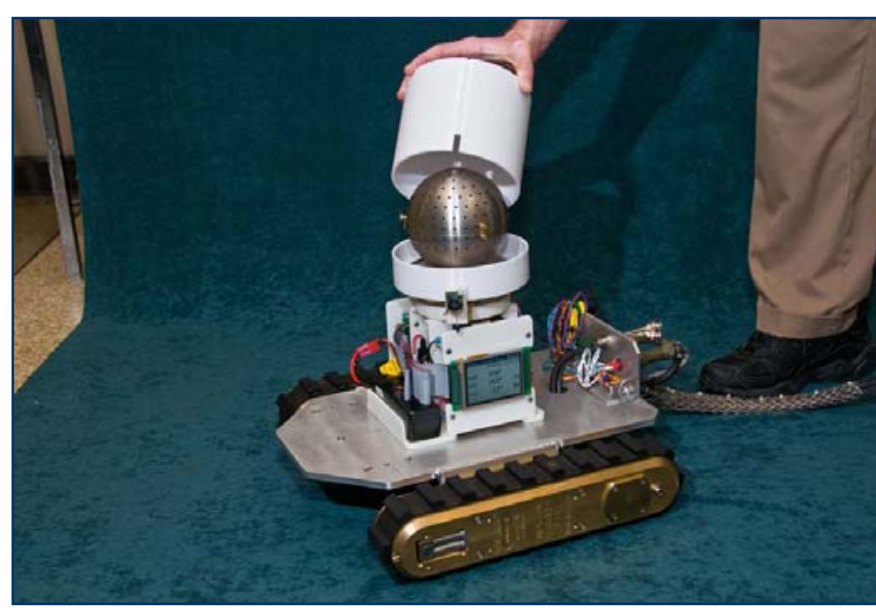

RadBall $^{\text {TM }}$ in PODS on robot 


\section{Remote Stack Characterization System}

Numerous stacks associated with gaseous waste treatment operations need to be characterized and demolished. Many of those stacks are several hundred feet tall and highly contaminated and/ or structurally deteriorated, making manual sample acquisition extremely hazardous. ORNL and Florida International University (FIU) are collaborating to develop and demonstrate a remote stack characterization system (SCS) that will facilitate the safe and cost-effective characterization and remediation of those structures and other similar elevated structures. During fiscal year 2010, design concepts and critical components were experimentally evaluated and the design concept updated with the experimentally acquired parameters. The detailed design drawing package for fabrication and the detailed design report were completed, and identified commercial off-the-shelf (COTS) components and fabrication of parts to be machined were procured. During fiscal year 2011, the entire system will be assembled, engineering tests performed,

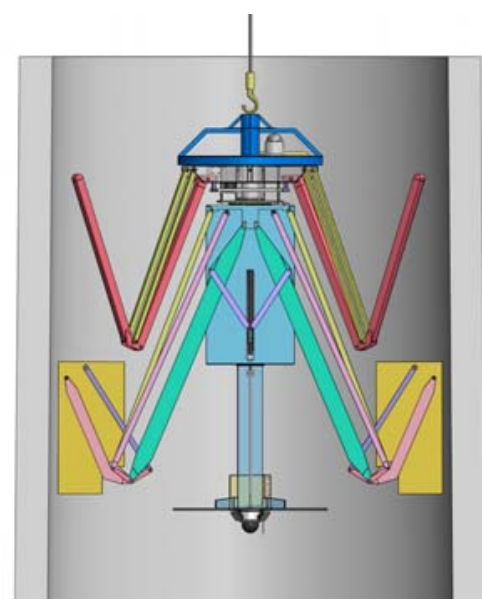

SCS inside stack and system performance demonstrated in the 7614 stack of the ORNL 7600 Robotics Complex in March 2011.

\section{Integrated Remote Fixative Spraying Platform}

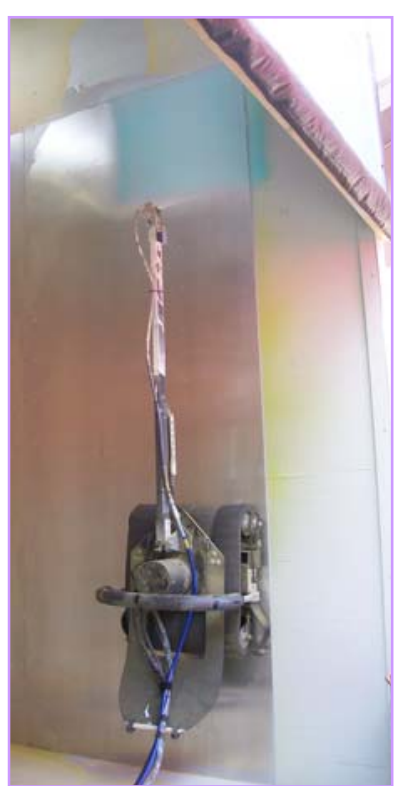

Integrated remote fixative spraying platform climbing up a vertical wall in mock hot cell and applying fixative to walls and ceiling
Another remotely operated technology need for D\&D is remote application of strippable/fixative coatings in hundreds of highly contaminated and access-limited hot cells to hold contamination in place during demolition. A study of COTS remote technologies for D\&D activities performed by FIU and NuVision Engineering found that no remotely operated technology exactly met the EM D\&D need. A remote fixative sprayer platform was identified and selected for integration with a commercially-available remotely operated platform developed by International Climbing Machine (ICM) that has the capability to climb vertical surfaces. Based upon an initial demonstration with fixative products at FIU in 2008 and specific technical requirements from DOE facilities, in June 2010 FIU and ICM conducted a second demonstration at ICM to evaluate the remote crawler machine's ability to spray strippable coatings and a decontamination gel on vertical surfaces of concrete and steel. The crawler was able to travel across the floor of the building module and climb the walls unassisted while being controlled remotely by the operator. The machine sprayed each product to the vertical wall surfaces to sufficient thickness to be stripped from the surfaces once dry. This innovative system provides a means to prepare the over 100 DOE hot cells complex-wide for D\&D while maintaining worker radiation exposure as low as reasonably achievable and without spreading radioactive contamination. 


\section{DeconGel ${ }^{T M}$}

EM has collaborated with Cellular Bioengineering, Inc. in the production and refinement of DeconGel $^{\mathrm{TM}}$ 1101, a decontamination gel (DG) that is spread or sprayed on a surface and allowed to cure before it is removed as a strippable film, taking contamination from the surface with it. The gel has been used across the DOE complex to decontaminate floors, walls, hot cells and gloveboxes contaminated with transuranic (TRU) nuclides. DG is water based and contains $<5 \%$ ethanol and other proprietary compounds, and these volatile organic compounds (VOCs) are released during application, curing and storage of the DG waste stream. The Waste Isolation Pilot Plant (WIPP) transportation criteria has established an upper limit of 500 parts-per-million by volume (ppmV) for VOCs in the head space of TRU waste containers. During fiscal year 2010, SRNL carried out experimental tests with the DG to demonstrate that total VOCs in the container head space are below the 500 ppmV limit. Therefore, DG can be used across the DOE complex with the knowledge that waste streams generated from TRU decontamination activities can be transported to WIPP for disposal if the radiological and chemical waste disposal criteria are met.

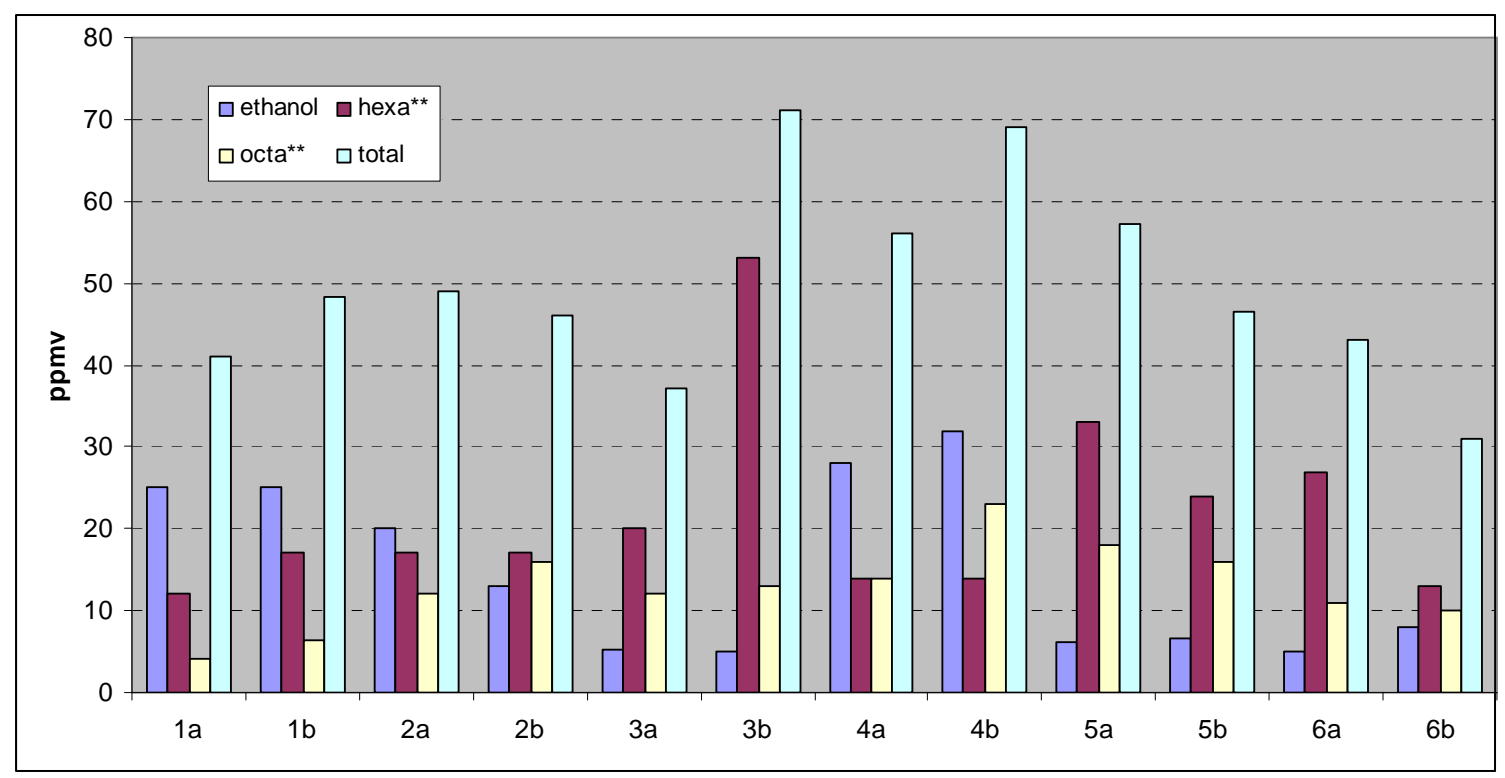

Results for headspace samples obtained from vessels holding DeconGel ${ }^{\mathrm{TM}}$. Duplicate results were obtained after 11 to 40 days and they indicate that the total VOC content is well below the WIPP transportation criterion of $500 \mathrm{ppmV}$. Note that error bars are \pm 20 percent, total is the sum of the measured analytes, and hexa** and octa** refer to proprietary ingredients in the DeconGel ${ }^{\mathrm{TM}}$. 


\section{Sodium Passivation}

The sodium-cooled Experimental Breeder Reactor (EBR)-II at the Materials and Fuels Complex at INL was in service from 1964 through 1994, after which it was shut down and drained. Most of the hundreds of gallons of radioactive sodium residue remaining on the walls and in hydraulic low points in the primary and secondary systems has been reacted ("passivated") with moist carbon dioxide into sodium bicarbonate. However, some nonpassivated sodium remains in locations that were inaccessible to passivation treatment or in pools of sodium that were too deep for complete penetration of the

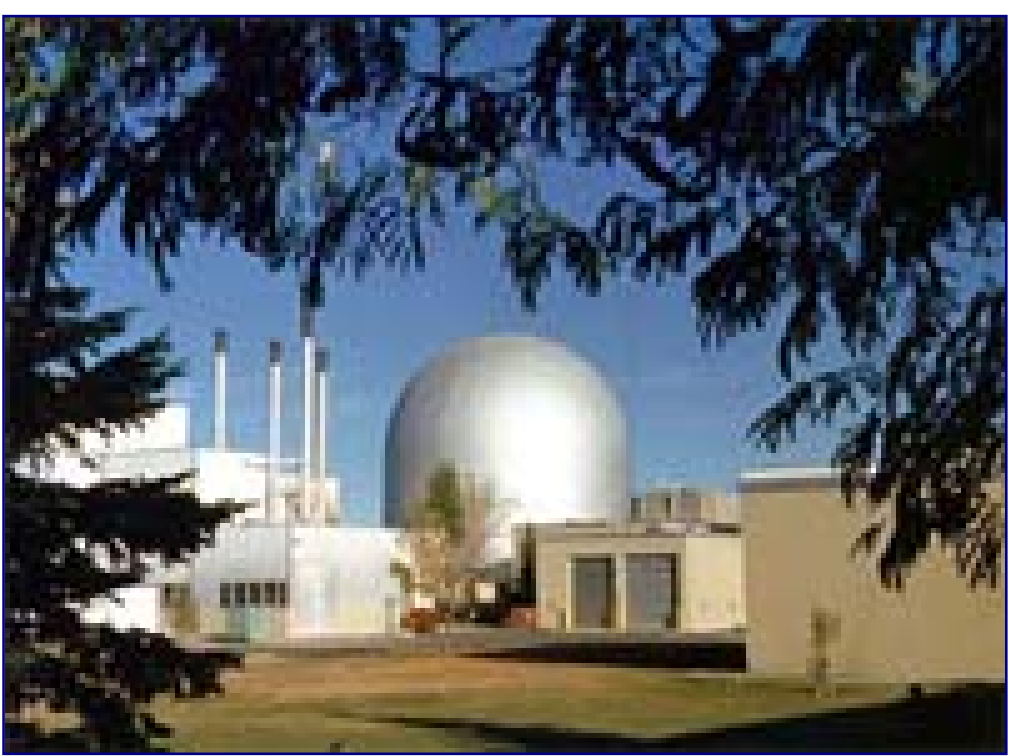

Experimental Breeder Reactor-II containment dome passivation treatment. The sodium must be treated or removed from the piping system and tanks to achieve clean closure for eventual $\mathrm{D} \& \mathrm{D}$ of the reactor. The proposed baseline closure method would have removed the large components from the primary tank, filled the primary system with water, reacted the remaining sodium with the water, and dissolved the reaction products in the wash water. That proposed baseline closure method would have generated a minimum of 100,000 gallons of caustic, liquid, low-level radioactive, hazardous waste water requiring disposal in a permitted facility. An alternative treatment method, Optimized Baseline Approach (OBA), consists of leaving all major components of the primary system in place and breaching certain components with a penetrating device to allow circulation of steam and wash water through the components. The primary system vessel would be filled with wash water and used to react and dissolve the majority of residual sodium left in the primary system. The OBA will neutralize the hazards, maximize byproduct removal, and minimize waste generation. During fiscal year 2010, the sodium passivation R\&D activity completed lab-scale testing and moved into bench scale and field-scale mock-up testing. Bench Scale studies using representative geometries optimized the chemistry and deployment method to successfully treat the sodium and potassium below the sodium bicarbonate layer. A field scale mock-up of the equipment has been fabricated and is ready to support testing.

\section{In Situ Decommissioning}

Fiscal year 2010 in situ decommissioning studies have focused on three of the six technology needs identified in Section 13 of the 2009 DOE EM Strategy and Experience for In situ Decommissioning report: 1) materials behavior and degradation; 2) monitoring; and 3) knowledge management. Concrete cores obtained from the SRS P Reactor Building were tested for compressive strength and chemical degradation components to assess the long-term physical and chemical stability of the structure. After 55 years, the compressive strength of the concrete is exceptional, as the present

\section{Environmental Management}


strength is twice that of the design specification. Initial tests on chemical degradation indicate that some of the Portland cement paste has been replaced with carbonate mineral calcite, which forms when carbon dioxide in the atmosphere reacts with the paste. This replacement reaction lowers the $\mathrm{pH}$ and can be detrimental to the enclosed iron rebar if the reaction penetrates deeply into the concrete. Present observations indicate the carbonation depth is no deeper than the outer 1 to 1.5 inches of the concrete. Suitable sensors and geophysical methods for passive long-term monitoring of ISD structures have been identified and purchased for functionality tests. Management of the knowledge across the DOE complex is a key strategy for sharing lessons learned, identifying emerging issues and technologies, and providing a single source for information and reporting to EM. SRNL has worked with FIU researchers to develop an EM web site to store and present the information: http://dndkm.arc.fiu.edu/dndkm.
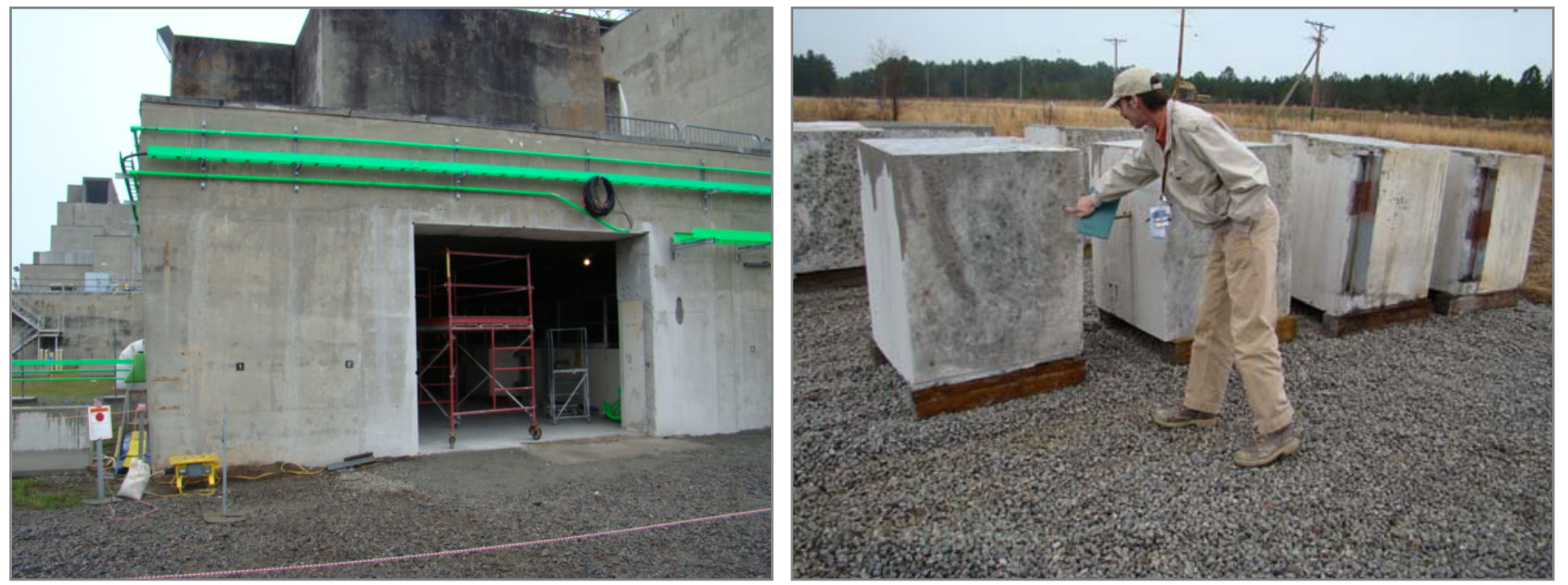

55-year-old concrete blocks removed from the P Reactor Building provided the initial concrete cores for compressive strength and chemical degradation tests. Stored at SRNL, the blocks will be sampled each decade to repeat the testing and assess the strength and degradation of the concrete over time. 
Editor Sheryl Ross Bush EM Technical Integration Office Savannah River National Laboratory 